\title{
O registro de marcas no Brasil e as imitações entre rótulos de cachaça de meados do século $\mathrm{XX}$ \\ Trademark registration in Brazil and imitations of cachaça labels from the middle of the 20th century
}

\author{
Swanne Almeida, Solange G. Coutinho
}

registro de marcas, rótulos de cachaça, imitações

Este artigo apresenta a trajetória do registro de marcas no Brasil, com ênfase em meados do século XX. Neste período, apesar de haver legislação específica protegendo as marcas de possíveis plágios, a prática de imitar rótulos de concorrentes era comum. Apresentamos casos de cópias encontrados na Coleção Almirante de rótulos de cachaça, analisando estes artefatos do ponto de vista compositivo, utilizando para tal fim alguns elementos da matriz de uso da linguagem gráfica de Twyman (1979).

trademark registration, cachaça labels, imitations

This article presents the development of trademark registration in Brazil, with particular emphasis on the mid-20th century. During this period, although specific legislation existed in order to protect trademarks from possible plagiarism, imitating the labels of competitors was a common practice. We therefore present cases of imitations encountered in the Almirante Collection of cachaça labels, and analyze these artifacts from a compositional viewpoint, using Twyman's (1979) matrix for the study of graphic language.

\section{Introdução}

A técnica litográfica no Brasil chega ainda no século XIX, passando a ser utilizada em conjunto com a tipografia. Como o Brasil não possuía treino na área impressora, os imigrantes europeus operavam inicialmente as máquinas, sendo natural o grafismo do período refletir também padrões europeus (Melo \& Ramos, 2011). As marcas das cachaças entre as décadas de 1940 e 1950 eram essencialmente rótulos compostos por tipografia ou litografia com temas variados. O registro era feito, na maioria das vezes, com o rótulo completo, sem a distinção de hoje de logotipo e símbolo. Já se observava uma tentativa de manter a identidade do produto quando o rótulo era reimpresso. Mas muitos ainda modificavam as marcas, mudando tipografias ou figuras ilustrativas. Também é comum encontrar rótulos de estoque ${ }^{1}$, provavelmente dos pequenos produtores que ainda não tinham essa preocupação com a exclusividade no mercado.

Apesar de haver decretos na legislação brasileira que regulavam o registro de marcas em meados do século XX, ainda eram encontradas muitas imitações, fossem na designação do produto, na estrutura compositiva do rótulo ou mesmo nos elementos ilustrativos repetidos. Sobre as ocorrências de possíveis imitações entre as rotulagens do período, Cunha Lima (1998) recolheu o depoimento de Seu Chiquinho, último proprietário da Gráfica Apollo, uma casa litográfica recifense do período. Em seu depoimento, Seu Chiquinho atestou que a clientela das casas litográficas normalmente trazia um modelo básico para servir como ponto de partida para o novo desenho. Ele mesmo admitindo já ter plagiado a si mesmo.

Neste contexto brasileiro, de multiplicidade de produtos, já havia a preocupação de proteger a marca de possíveis cópias. O registro de marcas era uma forma de proteção da marca, e no Brasil ele se inicia ainda na época do Império. Dentro desta conjuntura, apresentaremos neste artigo as formas de registro de marcas no Brasil a partir do final do século XIX até o início do século XX. Em seguida, analisaremos casos de imitações encontrados em exemplares de rótulos de cachaça das décadas de 1940 e 1950, provenientes da Coleção Almirante de rótulos

\footnotetext{
${ }^{1}$ Rótulos já impressos sem o título, o qual poderia ser acrescentado posteriormente por impressão tipográfica. Davidson (1989).
}

Anais do 8 CIDI e 8 CONGIC

Guilherme Santa Rosa; Cristina Portugal (orgs.)

Sociedade Brasileira de Design da Informação - SBDI

Natal | Brasil | 2017

ISBN 978-85-212-1305-5
Proceedings of the $8^{\text {th }} \mathrm{CIDI}$ and $8^{\text {th }}$ CONGIC

Guilherme Santa Rosa; Cristina Portugal (orgs.) Sociedade Brasileira de Design da Informação - SBDI

Natal| Brazil | 2017

ISBN 978-85-212-1305-5 
de cachaça (Fundação Joaquim Nabuco - FUNDAJ, Recife-PE). Para fins de análise, utilizaremos os modos de simbolização da linguagem gráfica proposta por Twyman (1979).

\section{0 registro de marcas no Brasil}

Conforme Rezende (2003), até 1875 o Brasil não possuía uma legislação específica para o registro e exclusividade de nomes ou imagens. A necessidade de proteger as marcas comerciais em circulação foi apenas percebida após um caso de plágio. Rezende (2003) cita que em 1873, a Meuron \& Cia que fabricava o rapé baiano nomeado "Arêa Preta", entrou com uma ação judicial contra a firma pernambucana Moreira \& Cia, pelo lançamento do Rapé Arêa Parda, que além de ter denominação semelhante também utilizava embalagem similar.

A Meuron \& Cia conseguiu apreender parte do material da fabricante pernambucana, mas teve que pagar custos de processo e prejuízo da concorrente, já que não havia ainda a Lei que indicasse o plágio como crime. Foi a partir deste incidente que o Brasil começou a elaborar a sua primeira legislação sobre o uso de marcas, incluindo nomes e imagens. As Juntas e Inspetorias do Comércio foram os órgãos competentes designados para realizar os registros e depósitos de marcas em todo o território nacional. Eis o Art. 1ํ do Decreto oㅡ 2.682, de 23 de outubro de 1875, que regulava o direito que têm o fabricante e o negociante, de marcar os produtos de sua manufatura e de seu comércio:

Art. 1 ㅇ É reconhecido a qualquer fabricante e negociante o direito de marcar os produtos de sua manufatura e de seu comércio com sinais que os tornem distintos dos de qualquer outra procedência. A marca poderá consistir no nome do fabricante ou negociante, sob uma forma distintiva, no da firma ou razão social, ou em quaisquer outras denominações, emblemas, estampas, selos, sinetes, carimbos, relevos, invólucros de toda a espécie, que possam distinguir os produtos da fábrica, ou os objetos de comércio.

Nota-se que o entendimento de marcas em 1875 abrangia uma gama de diversas apresentações, incluindo emblemas, selos, estampas, carimbos e invólucros de toda a espécie, abarcando desta forma os rótulos como um todo. Neste Decreto, ainda se expunha que não se consideravam como marcas apenas cifras ou letras, nem se admitiam imagens ou representações que pudessem suscitar escândalo. Para tornar a marca do produto exclusiva, o fabricante ou mandatário deveria apresentar dois exemplares do modelo para registro, um dos quais ficando colado em um livro próprio no Tribunal ou Conservatória do Comércio, como exposto a seguir:

Art. 3ํㅜㄹa este registro deverá o fabricante ou seu mandatário especial apresentar dois exemplares do modelo, dos quais um lhe será restituído com a nota do registro, e o outro colado em um livro próprio, que para esse fim haverá no Tribunal ou Conservatória do Comércio. O modelo consistirá no desenho, gravura ou impresso representando a marca adotada.

O Tribunal do Comércio, de que se fala esse Decreto, foi suprimido pelo Decreto no 2.662 de 9 de outubro de 1875, dando lugar às Juntas e Inspetorias Comerciais. Logo, o depósito passou a ser feito nas novas Juntas Comerciais. Rezende (2003) aponta que as marcas podiam ser apresentadas na Junta de diferentes maneiras, desde um esboço de uma imagem (figuras 1a e 1b) até um rótulo litografado completo (figura 2). A grande maioria dos registros, no entanto, utilizava os rótulos, que eram colados nos livros das juntas. Conforme Cunha Lima (1998), considerava-se para registro o todo da embalagem: imagem, nome do produtor e do produto.

Depois de depositada na Junta, a marca deveria ser publicada no Diário Oficial ou em qualquer outro jornal de grande circulação, com texto descritivo, data e hora do registro, além do nome do fabricante, também dono da marca. Um recorte desse jornal era encadernado junto à folha que continha o rótulo afixado, finalizando o processo de registro. A ideia de colocar a notícia do registro da marca em um jornal de grande circulação era torná-la de conhecimento público, sendo passível de punição ou contestação o uso irregular da mesma. Após todos os tramites, a marca estava protegida por Lei, sofrendo penalidades quem usasse tal nome ou imagem, como apresentado no Art. $7^{\circ}$ do Decreto 2.682 de 1875: Art. 7 Será punido com um a três meses de prisão e multa de 5 a $20 \%$ do dano causado, ou que se
poderia causar:

1ㅇ O que, sem contrafacção, imitar dolosamente marcas alheias de modo que possa enganar ao comprador; 


\section{CIDI 2017

$2^{\circ}$ O que no mesmo intuito e nas mesmas condições usar de marcas imitadas.

Esse sistema se manteve, basicamente até 1923, quando o registro de marcas passa para a esfera federal (Cunha Lima, 1998). Os livros-registro da Junta Comercial contendo os rótulos litografados foram recolhidos pelo Arquivo Nacional nas primeiras décadas do século XX.

Dessa forma, estes artefatos ficaram como patrimônio cultural, já que não têm mais nenhum valor legal. Durante visita realizada ao Arquivo Nacional em 2012, foi possível checar livros da Junta Comercial do Rio de Janeiro. Na época, a vistoria dos livros foi direcionada na busca por rótulos de aguardente ou ainda de outras bebidas. Abaixo, uma página de um dos livros vistoriados, de 1889, apresenta o rótulo de um vinho e sua descrição (figura 2).

Figuras 1a e 1b. Páginas do Livro de 1892 da Junta Comercial do Estado de São Paulo - JUSESP, com a página de abertura de Registro da marca de número 20 - da empresa Guimarães \& Cia (p. 134) e com o esboço da marca Andes que seria utilizada pela empresa, "para seus impressos" (p. 139). Acervo da JUSESP.
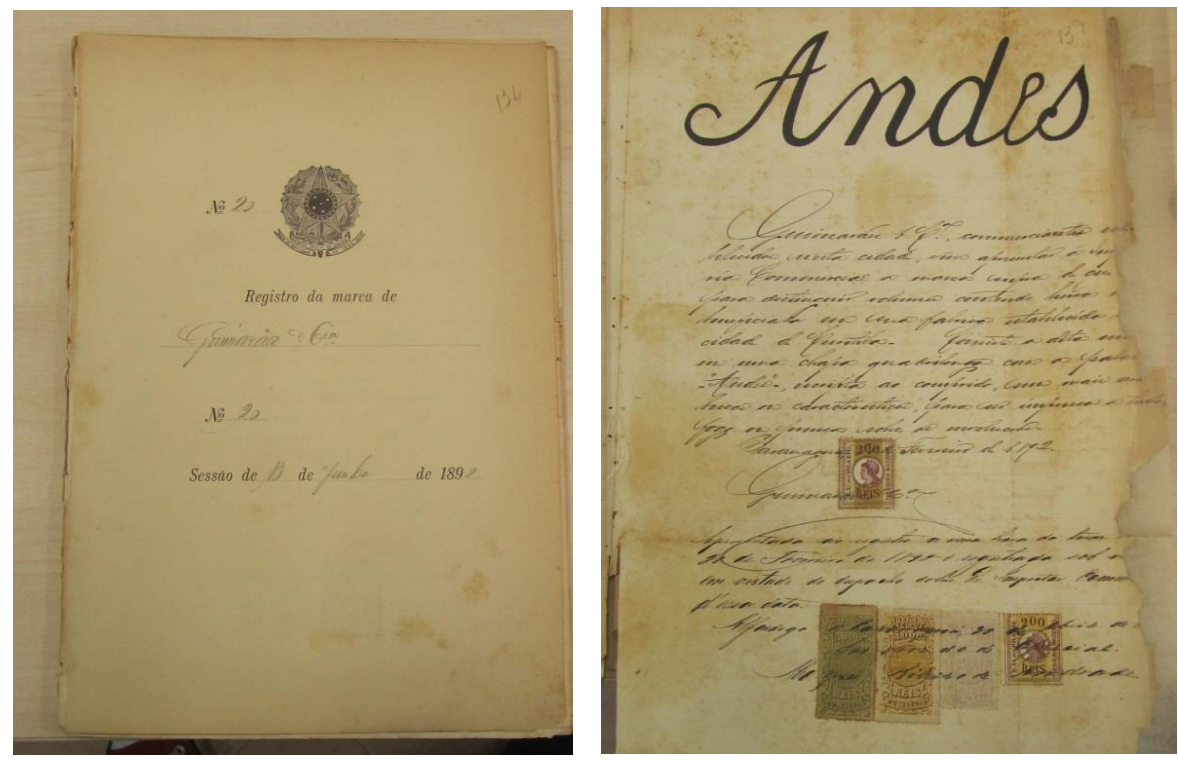

Figura 2. Página de Livro da Junta Comercial do Rio de Janeiro (IC372, 1889). Acervo do Arquivo Nacional.

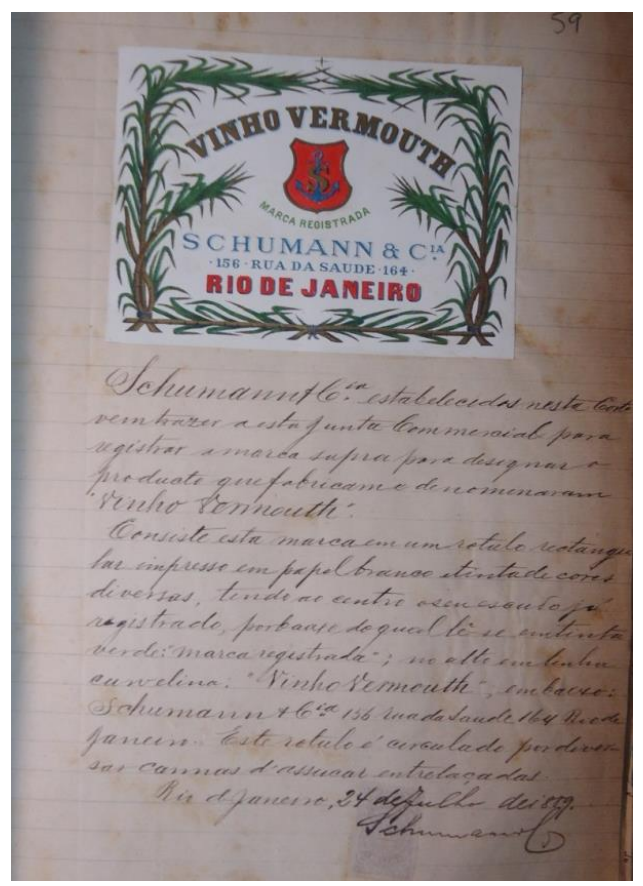


Em 1923, temos a criação da Diretoria Geral da Propriedade Industrial, a qual teve a seu cargo os serviços de patentes de invenção e de marcas de indústria e de comércio. Além dos exemplares para o registro, era requisitado especificamente o clichê tipográfico da marca. Em 1933, temos a aprovação do regulamento do Departamento Nacional de Propriedade Industrial. O depósito na Década de 1940, já não acontecia mais nas juntas comerciais, mas sim nesse departamento. O registro tinha um prazo de duração de dez anos.

Art. 126. O pretendente ao registro de marca de indústria ou de comércio, nome comercial, título de estabelecimento, insígnia e expressão ou sinal de propaganda deverá depositar no Departamento Nacional da Propriedade Industrial o seu pedido, acompanhado de três exemplares e de um clichê tipográfico.

No Decreto-Lei 2.848, de 7 de dezembro de 1940, encontramos no capítulo III as penalidades cabíveis nos casos de violação de marca, como exposto a seguir:

Art. 192. Violar direito de marca de indústria ou de comércio:

I - reproduzindo, indevidamente, no todo, ou em parte, marca de outrem registrada, ou imitando-a, de modo que possa induzir em erro ou confusão;

II - usando marca reproduzida ou imitada nos termos do n. I;

III - usando marca legítima de outrem em produto ou artigo que não é de sua fabricação;

IV - vendendo, expondo à venda ou tendo em depósito:

a) artigo ou produto revestido de marca abusivamente imitada ou reproduzida no todo ou em

parte; b) artigo ou produto que tem marca de outrem e não é de fabricação deste: Pena - detenção, de três meses a um ano, e multa, de um a quinze contos de réis.

Como veremos na próxima seção do artigo, apesar da legislação em vigor nessa época ser até mais específica e rigorosa em penalidades do que era no final do século XIX, ainda eram frequentes os casos de imitações nas rotulagens. Mais a frente, em 1945, encontramos o Decreto-Lei no 7903 de 27 de agosto de 1945. Este Decreto dispõe o código da Propriedade industrial. Esta proteção efetuava-se mediante a concessão de patentes, modelos de utilidade, modelos industriais, variedades novas de plantas, registro de marcas de indústria e comércio e afins, indicações de proveniência e repressão da concorrência desleal.

Nota-se que o código ampliou nesses anos suas medidas de proteção a outras instâncias. O título II do referido Decreto trata das marcas de indústria e de comércio, nome comercial, título de estabelecimento, insígnia e expressões ou sinal de propaganda, como descrito abaixo:

Das marcas registráveis

Art. 93. São suscetíveis de registro, como marca de indústria ou de comércio, entre outros, os nomes, palavras, denominações, conjunto de letras, algarismos, monogramas, emblemas, figuras, vinhetas, ornatos, desenhos, ilustrações, relevos, perfurações, transparências, estampas, recortes, rendilhados, impressões, gravuras, fotografias, sinetes, cunhos, selos, rótulos, e outros sinais distintivos de atividade industrial, comercial, agrícola ou civil.

Observa-se já de antemão que o registro não se restringe às marcas, estando agora mais bem elaborado, abarcando inclusive sinais de propaganda ou expressões. As marcas suscetíveis de registro também tiveram sua gama ampliada, incluindo, por exemplo, a fotografia. A seguir decorreremos os casos de imitações de rótulos encontrados na Coleção Almirante.

\section{As cópias encontradas na Coleção Almirante}

Aragão \& Barreto Campello (2011) já haviam observado recorrências nas produções da Coleção Imagens Comerciais de Pernambuco. Neste referido estudo, os autores documentaram recorrências nos elementos tipográficos e nas próprias composições gráficas dos rótulos. De modo similar, também foram encontrados na Coleção Almirante rótulos que possuem estruturas compositivas semelhantes ou mesmo praticamente copiadas. Elencamos aqui rótulos que contrariam o código de propriedade industrial de 1945, visto que as marcas e rotulagens podiam confundir o consumidor na hora de adquirir a bebida. Analisaremos, de forma descritiva, o uso da linguagem gráfica apontado por Twyman (1979), nos seus modos de simbolização (pictórico, esquemático e verbal), recorrente nesses artefatos. Elencaremos também dados informativos das cachaças, visto que é provável que as imitações decorressem daquelas mais populares no mercado no período. 


\section{Tatuzinho}

A Caninha Tatuzinho foi criada em 1950 pela família D'Ambrozo em Piracicaba, no estado de São Paulo. Esta marca tornou-se bastante popular no período, sendo difundida pelo território nacional. A marca possuía inclusive jargões como: Ai tatu, tatuzinho, me abre a garrafa e me dá um pouquinho. No portal do Youtube, encontramos até mesmo propagandas da bebida na década de 1960. Na Coleção Almirante, nos deparamos com dois exemplares da Caninha Tatuzinho, sendo um mais antigo e outro mais recente, de acordo com os órgãos de registro. $O$ rótulo mais antigo (década de 1950) traz como engarrafadores a "D'Ambrozo \& Companhia LTDA" e o mais recente (década de 1960) traz a "Tatuzinho Sociedade Anônima". Em termos de representação gráfica, o rótulo sofreu pequenas modificações. O tatu, elemento pictórico principal, foi espelhado e tornou-se mais detalhado e o listelo, que funciona como elemento esquemático teve suas terminações voltadas para cima. Os elementos verbais são semelhantes no caráter informacional e na anatomia tipográfica (figuras 3 e 4).

Figuras 3 e 4. Rótulo Tatuzinho (1950) e Rótulo Tatuzinho (1960). Coleção Almirante. Acervo FUNDAJ.
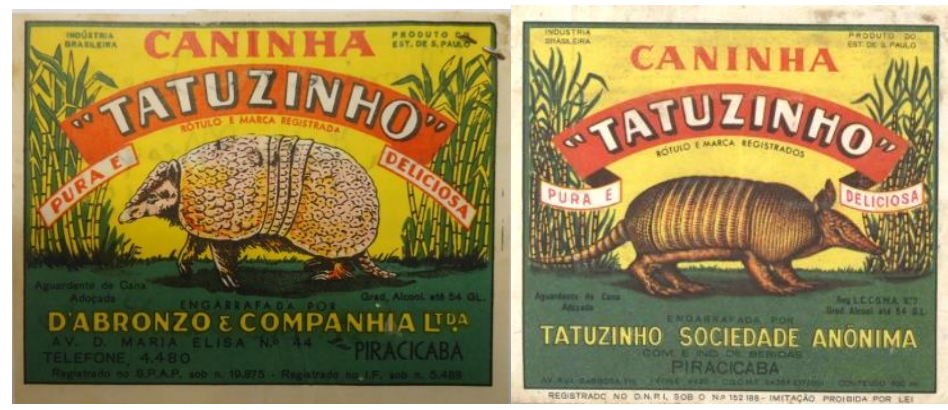

Além dos rótulos da Caninha Tatuzinho, encontramos uma série de rótulos utilizando uma linguagem gráfica semelhante:

- Elementos pictóricos: uma espécie de canavial nas laterais, fundo amarelo e gramado verde; desenho de um animal preferencialmente andando de perfil;

- Elementos esquemáticos: um listelo vermelho curvilíneo localizado na parte superior do rótulo com a designação da marca estampada;

- Elementos verbais: designação da bebida em caixa-alta na cor branca com contorno preto.

Listamos aqui três das ocorrências, ressaltando que ainda há outras na Coleção Almirante: Raposinha (figura 5), Cabreuva (figura 6) e Carneirinho (figura 7). Raposinha e Cabreuva são marcas do estado de São Paulo, mas Carneirinho provém do Paraná, demonstrando a popularização da Caninha Tatuzinho em território nacional.

Observa-se que a estrutura compositiva do rótulo é a mesma nos três exemplares. As tipografias mudam ligeiramente no olhar do especialista, mas não devem fazer diferença para o consumidor. Os animais andam de perfil tal qual o Tatuzinho, e muitos deles tem sua designação em diminutivo: raposinha, carneirinho, tourinho; como também a mesma tipificação: caninha.

Figuras 5, 6 e 7. Rótulos Raposinha, Cabreuva e Carneirinho (estimados na década de 1950). Coleção Almirante. Acervo FUNDAJ.
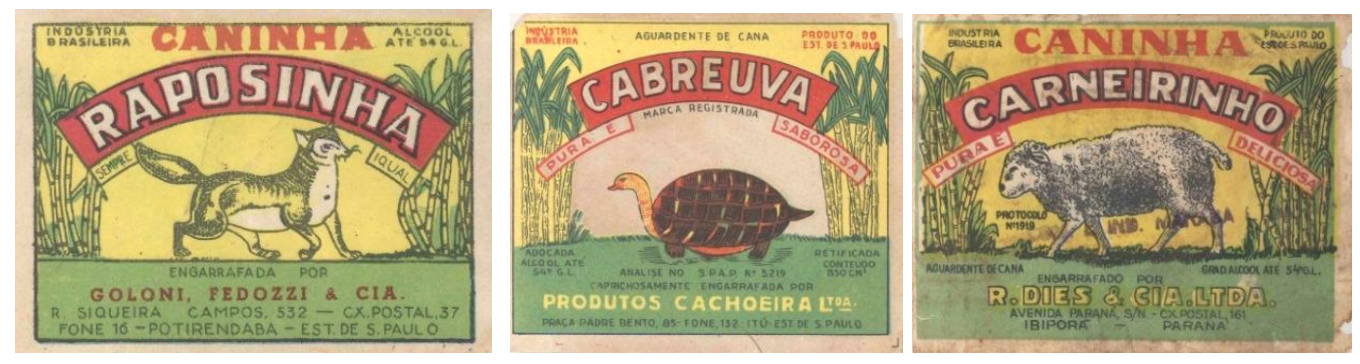

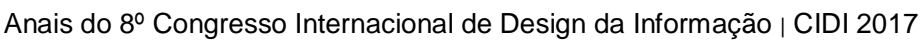

Proceedings of the $8^{\text {th }}$ Information Design International Conference | CIDI 2017 


\section{CIDI 2017 8n $^{\text {gnd }}$

\section{Serra Grande}

A Serra Grande foi uma aguardente que começou em 1898, com produção familiar nos engenhos da Fazenda Serra Grande, na cidade de Vitória de Santo Antão no estado de Pernambuco. O patriarca da família, Jair Pinto do Rêgo, tomava frente à produção. Inicialmente a designação da aguardente era "Imaculada", escolhida no lugar de Serra Grande, contudo, como o nome "Serra Grande" aparecia em tamanho maior no rótulo, este último acabou sendo adotado pelos próprios consumidores, forçando a marca a torná-lo legítimo.

O rótulo da Serra Grande é basicamente composto por um fundo amarelo e uma moldura de cana-de-açúcar nas laterais, com sua designação e as informações referentes à bebida dispostas centralizadas no espaço provido pela moldura. Em $1989 \mathrm{com}$ o falecimento do dono, a família acabou decidindo pelo arrendamento da marca, e a produção ficou apenas de forma artesanal no interior.

Encontramos na Coleção Almirante um exemplar do rótulo da Serra Grande (figura 8). Neste exemplar, a designação "Imaculada" ainda está presente na parte superior do rótulo, em letras maiúsculas na cor amarelo, oferecendo menor contraste e hierarquia do que o nome "Fazenda Serra Grande", praticamente no centro do rótulo, em letras maiores e vermelhas. O rótulo estimado do início da década de 1940, já trazia premiações nacionais e internacionais da aguardente em exposições realizadas nos anos de 1908, 1910 e 1911.

Figura 8. Rótulo da Serra Grande (1940). Fonte: Coleção Almirante. Acervo FUNDAJ.

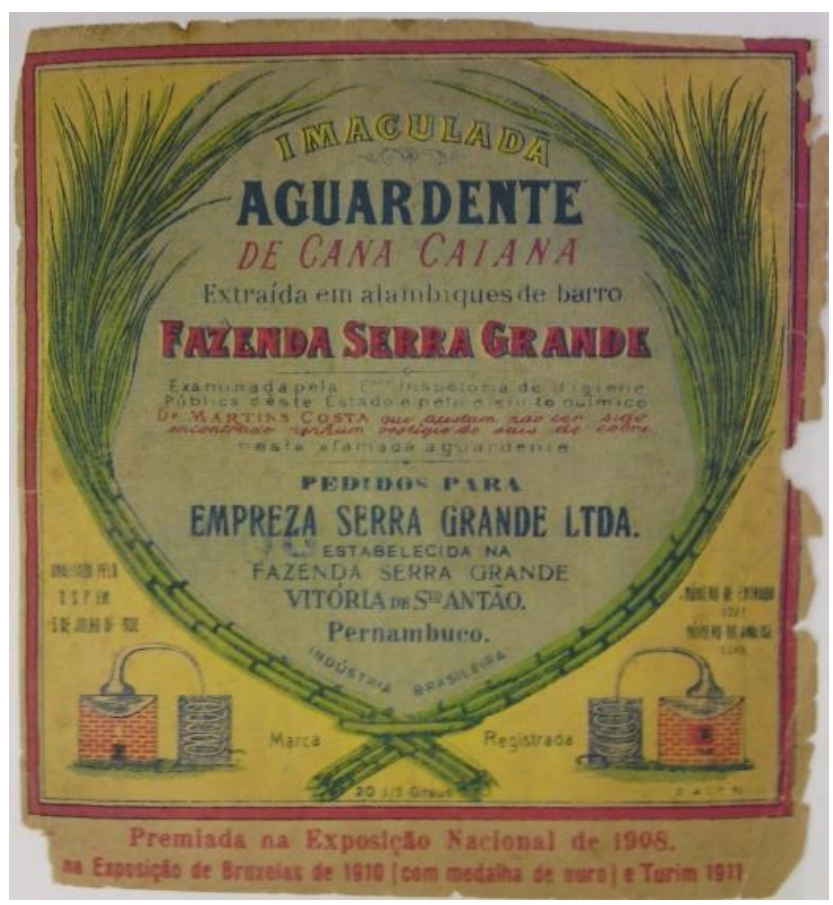

Em virtude de sua popularidade, acreditamos que os rótulos encontrados com linguagem gráfica semelhante façam referência a esta aguardente. Dentre alguns encontrados, selecionamos: a Aguardente Fazenda do Norte (figura 9), a Aguardente Serra Longa (figura 10) e a Distinguida Estrela do Norte (figura 11). A Fazenda do Norte e a Serra Longa têm procedência de Pernambuco, mas os engarrafadores são do Rio de Janeiro; já a Estrela do Norte só traz referências do Rio de Janeiro. Podemos indicar as seguintes semelhanças:

- Elementos pictóricos: a cana-de-açúcar que é ilustrativa e ao mesmo tempo auxilia na organização da informação, numa configuração semelhante a de um 'brasão';

- Elementos verbais: a designação de todas vem em letras no formato caixa-alta em vermelho;

- Os três rótulos apresentam o mesmo fundo amarelo da Serra Grande. 


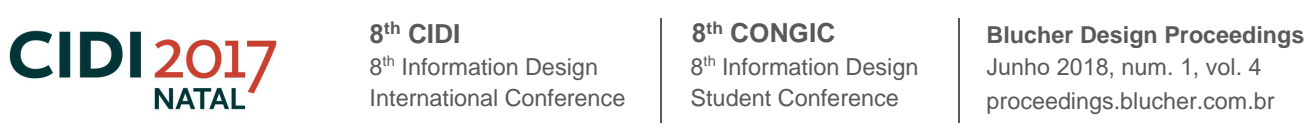

Figuras 9, 10 e 11. Aguardente Fazenda do Norte, Aguardente Serra Longa e Distinguida Estrela do Norte (estimados entre as décadas de 1940 e 1950). Fonte: Coleção Almirante. Acervo FUNDAJ.

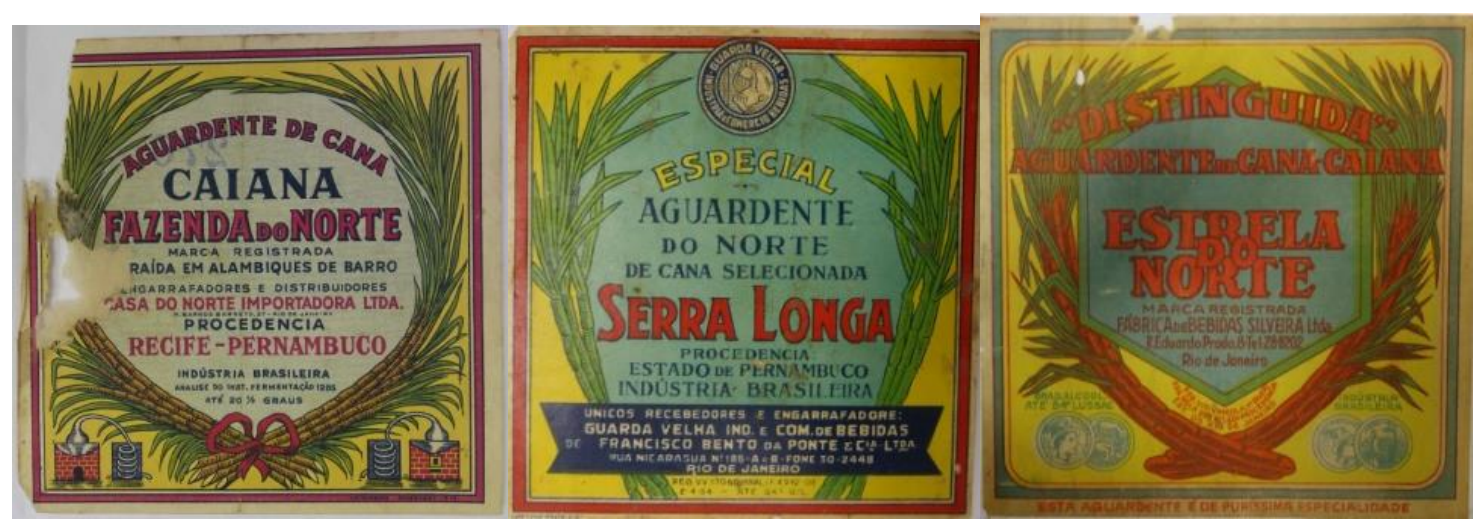

\section{Pitú}

A Pitú é uma empresa pernambucana de longa data. Fundada em 1938 na cidade de Vitória de Santo Antão, no estado de Pernambuco, pelos senhores Joel Cândido Carneiro, Severino Ferrer de Morais e José Ferrer de Morais. Segundo informações disponíveis no site pitu.com.br, no início a empresa trabalhava com a fabricação de vinagre e bebidas à base de maracujá e jenipapo, além do engarrafamento de aguardente. Em 1948, com o ritmo de crescimento acelerado, a empresa ganhou o nome de Engarrafamento Pitú LTDA.

Quanto ao uso do elemento ilustrativo de um pitu - crustáceo de água doce, também conhecido como lagostim, segundo o antigo diretor presidente, senhor Elmo Cândido Carneiro, existem duas versões para a escolha do nome da empresa. Uma das versões faz referência ao nome Engenho Pitú, propriedade da família em Vitória de Santo Antão, na qual havia muitos pitus, os crustáceos de água doce, usados como tira-gosto das reuniões para beber aguardente no engenho. A outra versão fala da cana-pitu, um tipo de cana-de-açúcar dos engenhos da mata norte.

Ainda segundo informações do site, o primeiro rótulo foi criado pelo amigo dos fundadores, o desenhista e apreciador de cachaça Henrique de Holanda Cavalcanti, que desenhou o rótulo com giz de cera em cima de um papelão. Segundo a pesquisa de Cunha Lima (1998), Seu Chiquinho que foi funcionário e proprietário da Gráfica Apollo, teria sido o responsável pelo desenho. Podemos inferir pela forma como a clientela se dirigia às gráficas, que o desenho de Henrique de Holanda Cavalcanti foi o esboço levado para Gráfica, o qual foi redesenhado e remodelado às condições técnicas por Seu Chiquinho.

A marca da aguardente Pitú se consolidou no mercado entre as décadas de 50 e 80, com o aumento de sua produção, comercialização e participação de mercado. Seu exemplo como uma cachaça que traz rótulos similares, já foi abordado por Coutinho (2011), Almeida (2013), Almeida \& Coutinho (2015). O rótulo original da Pitú é caracterizado por um pitu em fundo preto e a designação (Pitú) em caixa-alta nas cores vermelho e amarelo, posicionada no campo direito do rótulo. As ondulações em vermelho e amarelo na parte inferior do rótulo, dedicadas à engarrafadora e ao endereço, também são artifícios marcantes do rótulo.

Dentre as cachaças que trazem imitações, a Pitú (figura 12) foi sem dúvida, ao menos na Coleção Almirante, aquela que possui mais imitações. As recorrências acontecem em especial nos rótulos pernambucanos. Encontramos imitações em alto grau na linguagem gráfica e ainda um exemplar, cujo próprio nome faz uma analogia a Pitú, é o caso de Bitu (figura 14), é só trocar o "B" de Bitu, pelo "P" de Pitú, além de Tatú (figura 13). Apesar de Pernambuco ser de fato o estado onde essa recorrência predominou visualmente, encontramos, em escala bem menor, exemplos de imitações em outros estados, como o rótulo Perú (figura 15) do estado do Rio de Janeiro. Vale ressaltar que para além dos elementos da linguagem gráfica todas as denominações possuem quatro letras. Como semelhanças podemos ainda elencar:

- Elementos pictóricos: a representação de um animal, utilizando especialmente a cor vermelha e localizada na parte superior esquerda do rótulo; 


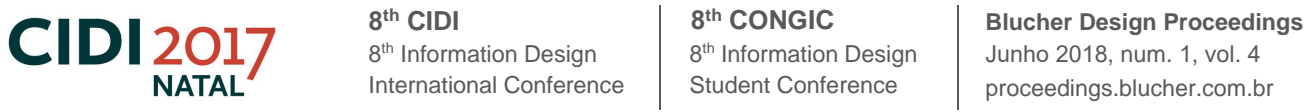

- Elementos esquemáticos: ondulações ou faixas nas cores vermelho e amarelo, nas quais informações como o engarrafamento e o estado de procedência da bebida são dispostas;

- Elementos verbais: a designação em caixa-alta com contorno, utilizando as cores vermelho e amarelo especialmente, estando localizada no lado direito, abaixo do animal;

- O padrão cromático "preto, vermelho e amarelo" se mostrou bem recorrente em Pernambuco, se estendendo até as outras temáticas, além dos animais. Este fato nos faz considerar também a hipótese de que este trio de cores era uma característica do período em Pernambuco, que pode ter sido potencializada com a popularidade da Pitú.

Figuras 12, 13, 14 e 15. Rótulos Pitú, Tatú, Bitu e Perú. Estimados na década de 1950. Fonte: Coleção Almirante. Acervo FUNDAJ.
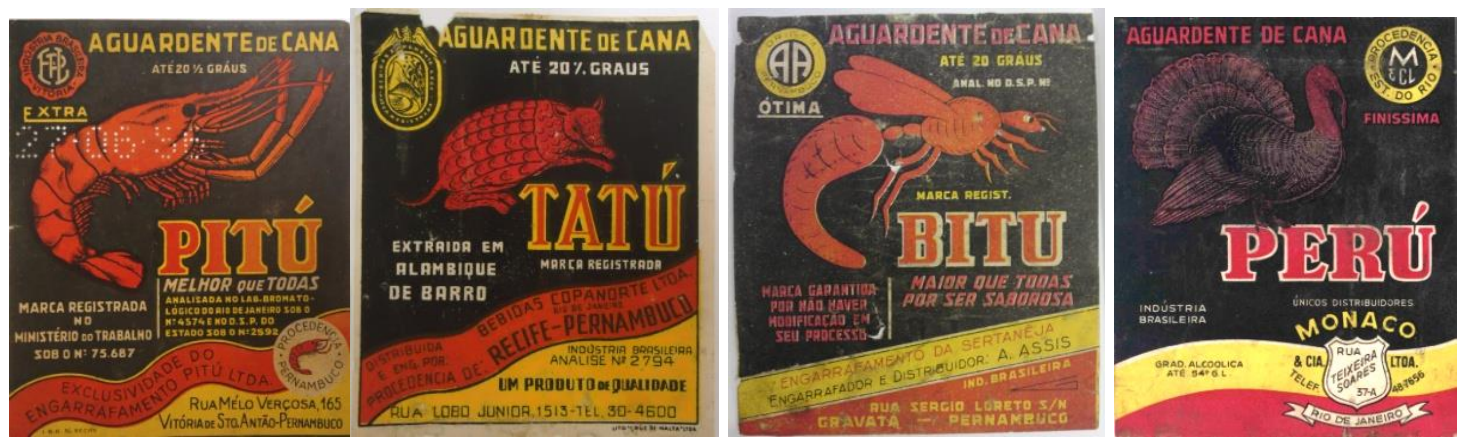

\section{A Colonial e a Continental}

A Cachaça Colonial surgiu em 1923, no Sítio Colégio na cidade de Aquiraz, no estado do Ceará. A iniciativa foi de Tibúrcio Targino que implantou novos métodos de plantio e produção de aguardente no Ceará e criou a marca, que se tornou uma das mais tradicionais do país. A Cachaça Colonial vem passando de geração em geração e está até hoje no mercado.

Encontramos na Coleção Almirante um rótulo desta cachaça, estimado na década de 1940. A bebida, segundo consta no rótulo, é fabricada e engarrafada pelos Herdeiros de Tiburcio Targino.

Figuras 16 e 17. Rótulo da cachaça Colonial e seu similar Continental, estimados na década de 1940. Fonte: Coleção Almirante. Acervo FUNDAJ.
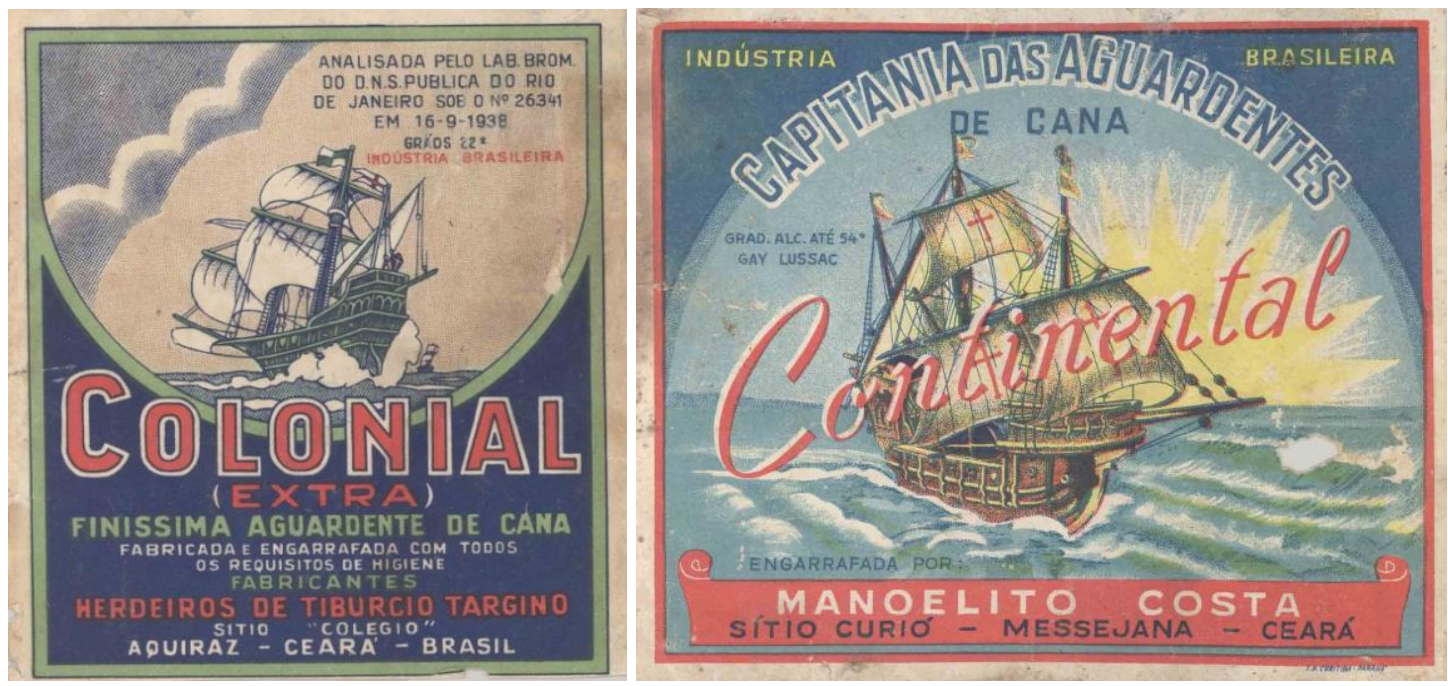

A marca da Colonial (figura 16) era composta por uma caravela navegando no mar como elemento pictórico, com o nome Colonial em seu centro em caixa-alta e em letras vermelhas, utilizando como base um fundo azul escuro. Encontramos no estado do Ceará, um rótulo que acreditamos ser uma imitação da marca, adotando o nome de "Continental" (figura 17), que sonoramente se assemelha a "Colonial" e utiliza também uma caravela navegando como 


\section{CIDI 2017 告 cold

elemento pictórico. A linguagem gráfica não é tão semelhante como no caso das marcas recorrentes da Pitú e Tatuzinho, contudo, a Continental apela para o mesmo conceito utilizado pela marca Colonial - 0 de expedições marítimas.

\section{Pirassununga 1921}

A semelhança entre rótulos com a Pirassununga 1921, já foi mencionada em Almeida (2013) e Almeida \& Coutinho (2015: 990). Esta cachaça é produzida pela Indústria de bebidas Pirassununga, possuindo mais de 80 anos no mercado.

Figura 18. Rótulo Caninha Pirassununga 1921 original. Estimado na década de 1950. Disponível em: http://www.riopostal.com/detalhes_produto.asp?id=9647\&url_foto=L\%20387.jpg\#.

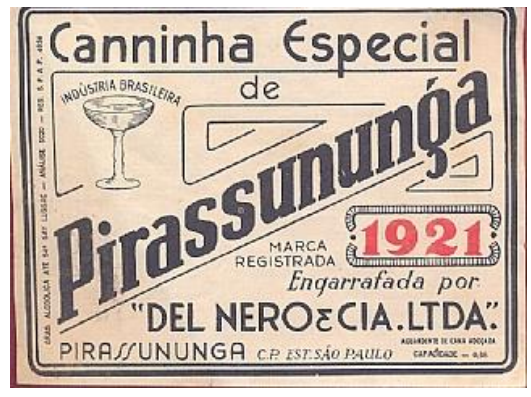

O rótulo é marcado pelo não uso da linguagem pictórica, pela designação em diagonal em tipografia característica, com o uso de elementos esquemáticos, como linhas na organização da informação (figuras 19, 20 e 21).

- Elementos esquemáticos: as mesmas linhas ao redor da designação;

- Elementos verbais: designação no formato caixa-alta e caixa-baixa na cor preta em tipografia serifada, podendo ou não também estar associada a um ano na cor vermelha.

Figuras 19, 20, e 21. Rótulos Pirassununga, Prateadinha 1951 e Pirassununga 1941 do estado de São Paulo (estimados entre as décadas de 1940 e 1950). Fonte: Coleção Almirante. Acervo FUNDAJ.
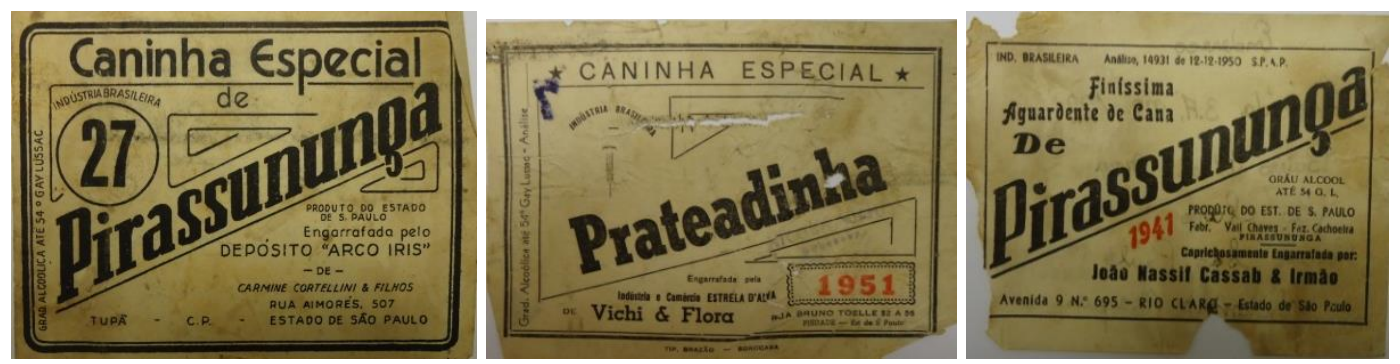

\section{A Aguardente Madeira de Lei e a Aguardente Veterana de Lei}

Nestes dois exemplos (figuras 22 e 23), não sabemos quem provavelmente imitou quem. A estrutura é parecidíssima. Observamos as semelhanças abaixo:

- Elementos Pictóricos: espécie de construção vertical (obelisco e torre), centralizado e representações da cana-de-açúcar nas laterais do rótulo;

- Elementos esquemáticos: listelo curvilíneo, no qual se localiza a designação e caixa vermelha no campo inferior do rótulo;

- Elementos verbais: designação em tipografia que mistura caixa-alta e capitulares, na cor vermelha com uso de sombra, dando aspecto de tridimensionalidade. Outros elementos verbais se dividem no meio do rótulo e no quadro vermelho, existente em ambos os rótulos. Até a frase de autenticidade que utilizam é a mesma: Só é legítima tendo nos selos as iniciais V.P.R (no caso de Madeira de Lei) e A.G.R. (no caso de Veterana de Lei). As iniciais correspondem em Madeira de Lei ao fabricante e em Veterana de Lei, ao distribuidor. Ambas as bebidas provém do município de Acarapé no Ceará. 


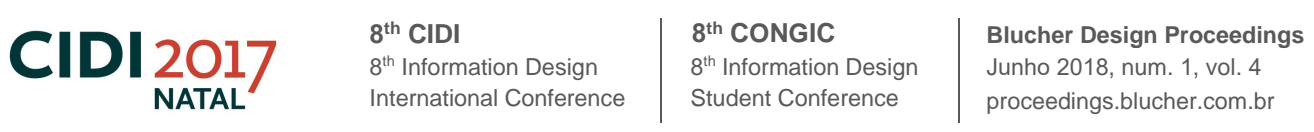

Figuras 22 e 23. Rótulos Aguardente Madeira de Lei e Aguardente Veterana de Lei (estimados entre as décadas de 1940 e 1950). Fonte: Coleção Almirante. Acervo FUNDAJ.
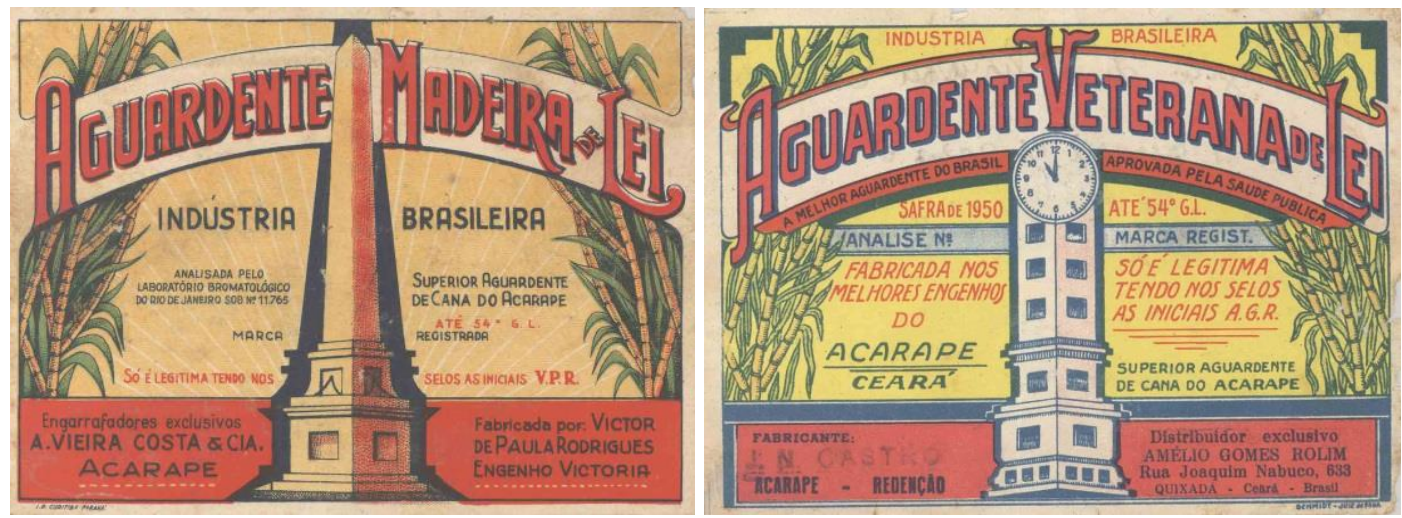

As terras de Acarapé, no século XVIII, foram beneficiadas com a agricultura da cana-deaçúcar, devido à fertilidade do solo e abundância de água. Com estes atributos, foram criados engenhos e alambiques no município. Portanto, a história da produção da aguardente nesta localidade é antiga, cabendo associações como "Madeira de Lei", que são as madeiras que por sua qualidade e resistência duram mais que as outras; e também "Veterana de Lei", cuja palavra "veterana" pode denotar que a marca é experiente na área.

\section{Chamego, Esmeralda e Brotinho}

Foram encontrados pelo menos cinco exemplares de diferentes produtores utilizando a mesma ideia para marca. Elemento pictórico de uma mulher em trajes de banho de corpo inteiro, arrematada por elemento esquemático composto por uma faixa vermelha com a designação. Estes exemplares não configuram rótulos de estoque, pois todas as mulheres e faixas são desenhos diferentes, mas a semelhança é inegável. Ainda não sabemos qual exemplar representaria a ideia original, se alguma dessas bebidas era popular e foi utilizada como referência, se é uma referência a um evento externo, como a aparição de alguma personalidade ou ainda um filme, ou mesmo uma ideia feita em uma gráfica que acabou sendo copiada por outras.

Figuras 24, 25 e 26. Rótulos Chamego, Esmeralda e Brotinho (estimados entre as décadas de 1940 e 1950). Fonte: Coleção Almirante. Acervo FUNDAJ.
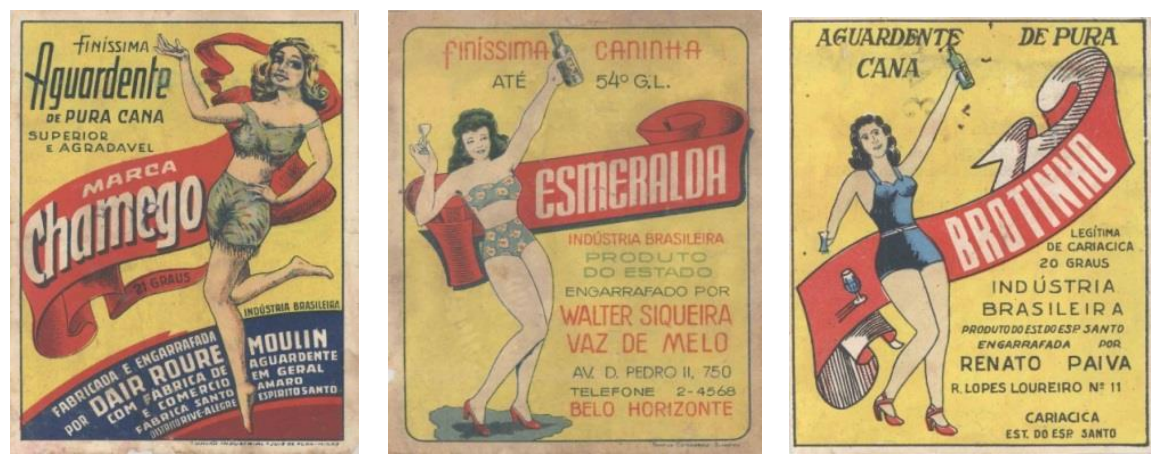

\section{Sabiá, Chavinho, Japy, Bentevi}

Sabiá, Chavinho, Japy e Bentevi são exemplos de possíveis rótulos de estoque com pequenas modificações, contudo também caracterizam uma produção buscando modelos compositivos semelhantes, visto que todos recorrem a pássaros como representações da marca.

- Elementos pictóricos: pássaros e cana-de-açúcar na lateral esquerda do rótulo. Os desenhos são semelhantes, mas não são idênticos, passaram provavelmente por ajustes na matriz;

- Elementos esquemáticos: um listelo nas cores vermelho e branco, que serve de apoio para o desenho do pássaro e a designação; uma moldura verde delineando o rótulo; 
- Elementos verbais: não foram observadas semelhanças na anatomia tipográfica, mas podemos dizer que todos exemplares utilizam sua designação no formato caixa-alta;

- O fundo amarelo também foi repetido.

Figuras 27, 28, 29 e 30. Rótulos Sabiá, Bentevi, Chavinho e Japy (estimados entre as décadas de 1940 e 1950). Fonte: Coleção Almirante. Acervo FUNDAJ.
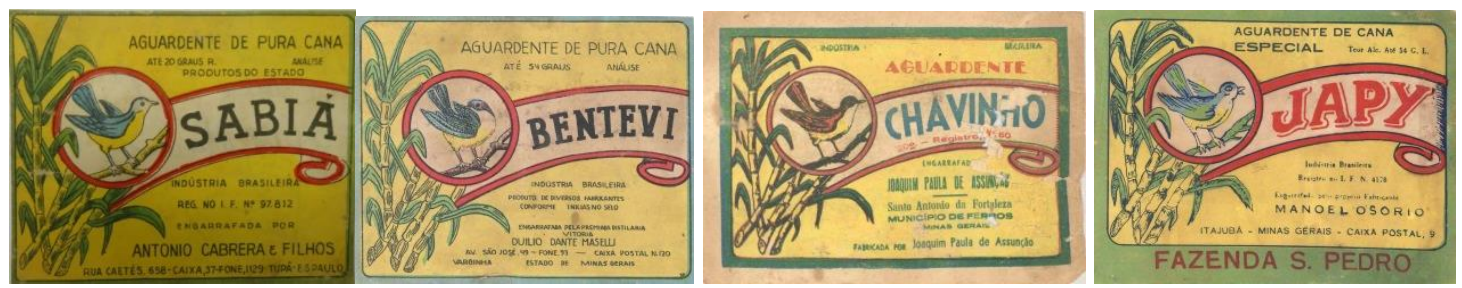

\section{Considerações finais}

Diante do exposto, observamos que o registro de marcas no Brasil, apesar de ter surgido no intuito de proteger legalmente e distinguir a multiplicidade de produtos no mercado, não extinguiu as imitações entre marcas. Na época da Coleção Almirante, entre 1940 e 1950, vimos que o registro já não acontecia mais nas Juntas Comerciais, o responsável pelas questões relativas ao registro de marcas era o Departamento Nacional de Propriedade Industrial.

Notamos que já havia um código penal neste período a fim de coibir imitações, mas o costume em recorrer a padrões compositivos nas casas litográficas ainda era muito forte. Visto que, uma prática do período era a clientela levar às casas litográficas exemplos de rótulos para servirem de modelos para o desenho de suas marcas. Observamos também que as semelhanças se davam tanto no campo sintático, como no uso de elementos pictóricos equivalentes, tipografias de anatomia semelhante, mesmo padrão cromático; como também afinidades no campo semântico, na escolha de designações de fonética e significados semelhantes.

\section{Agradecimento}

A todos os colaboradores da Fundação Joaquim Nabuco - FUNDAJ.

\section{Referências}

ALMEIDA, S. S. T. 2013. O sistema informacional de rótulos de cachaça brasileiros: o estudo comparativo entre os estados de Pernambuco, Rio de Janeiro e São Paulo. Dissertação de Mestrado não publicada. Departamento de Design. Universidade Federal de Pernambuco UFPE, Recife.

ALMEIDA, S. S. T.; COUTINHO. S. G. 2015. Considerações sobre a Coleção Almirante (Pernambuco, Rio de Janeiro e São Paulo). In: C. G. Spinillo; L. M. Fadel; V. T. Souto; T. B. P. Silva \& R. J. Camara (Eds). Proceedings of the 7th Information Design International Conference / CIDI 2015 [Blucher Design Proceedings, num.2, vol.2]. São Paulo: Blucher, p. 979-992.

ARAGÃO, I. R.; BARRETO CAMPELLO, S. 2011. Referências, recorrências e cópias nos elementos verbais da Coleção Imagens Comerciais de Pernambuco (ICP). In: Anais do 5o Congresso Internacional de Design da Informação, 2011, Florianópolis.

COUTINHO. S. G. 2011. O sistema informacional nos rótulos comerciais de cachaça em Pernambuco (1940-1970). In: BARRETO CAMPELLO, S.; ARAGÃO, I.R. (Org.). Imagens Comerciais de Pernambuco: Ensaios sobre os efêmeros da Guainases. Recife: Néctar.

CUNHA LIMA, E. L. 1998. Cinco décadas de litografia comercial no Recife: Por uma história das marcas de cigarro registradas em Pernambuco. Dissertação (mestrado). Departamento de Artes \& Design. PUC-Rio, Rio de Janeiro. 
DAVIDSON, J. 1989. The art of the cigar label. New Jersey: The Wellfleet Press.

MELO, C. H de.; RAMOS, E. 2011. Linha do Tempo do Design Gráfico no Brasil. São Paulo: Cosac Naify.

PITÚ. 2017. Nossa história. In: Sobre Nós: Nossa história. < http://www.pitu.com.br/sobrehistoria>, 20/01/2017.

REZENDE, L. L. 2003. Do projeto gráfico ao ideológico: a impressão da nacionalidade em rótulos oitocentistas brasileiros. Dissertação de mestrado não publicada. Departamento de Artes \& Design. PUC-Rio, Rio de Janeiro.

TWYMAN, M. L. 1979. A schema for the study of graphic language. In: Paul A. Kolers, Merald E. Wrolstad \& Herman Bouma (Org.). Processing of visible language. Nova York \& Londres: Plenum Press, v.1: 117-150.

\section{Sobre o(a/s) autor(a/es)}

Swanne Almeida, Doutoranda, UFPE e IFPE, Brazil <swanne.almeida@gmail.com> Solange G. Coutinho, PhD, UFPE, Brazil <solange.coutinho@globo.com> 